\title{
Factors influencing quality of life up to the 36th month follow-up after treatment of acute coronary syndrome by coronary angioplasty
}

This article was published in the following Dove Press journal:

Nursing: Research and Reviews

14 January 2015

Number of times this article has been viewed

\author{
Izabella Uchmanowicz' \\ Krystyna Łoboz-Grudzień ${ }^{1,2}$ \\ 'Department of Clinical Nursing, \\ Public Health Department, Wroclaw \\ Medical University, Wroclaw, \\ Poland; ${ }^{2}$ Department of Cardiology, \\ T Marciniak Memorial Hospital, \\ Wroclaw, Poland
}

Purpose: Patients with acute coronary syndrome (ACS) constitute a very diverse group in terms of the severity and course of the disease, pharmacotherapy applied, and effort tolerance. Moreover, medical diagnosis is not always accompanied by patients' subjective assessment of their health status and health-related quality of life (HRQOL). Hence, the objectives of this paper are as follows: i) to compare HRQOL of patients receiving percutaneous coronary intervention (PCI); ii) to detect whether depressive symptoms and the level of anxiety have an influence on the HRQOL; iii) to determine the dynamics of changes in the HRQOL of patients after PCI; and iv) to find any differences in the HRQOL of patients along lines of sex.

Patients and methods: The study involved 90 patients ( 55 men, 35 women) aged 39-84 hospitalized due to ACS and who qualified for coronary angioplasty. HRQOL was measured using the Medical Outcomes Study 36-item Short-Form Survey, and analysis of depressive symptoms was performed using the Beck Depression Inventory. The level of anxiety was determined using modified State-Trait Anxiety Inventory.

Results: Analyses of the dynamics of changes in the physical and mental domains revealed an unfavorable trend in the 36th month after surgery. The dynamics of change in the severity of depressive symptoms according to the Beck Depression Inventory showed an increase from 4.6 in the first week to 10.4 points in the 36th month. Changes in the levels of anxiety as a state and anxiety as a trait showed an unfavorable trend.

Conclusion: The results of the study showed that more attention should be paid to anxiety accompanying cardiovascular diseases. There is a relationship between HRQOL and such variables as sex, age, anxiety and depressive symptoms. The results suggest that more attention should be focused on the distant quality of life of ACS patients after PCI.

Keywords: acute coronary syndrome, quality of life, percutaneous coronary interventions

\section{Introduction}

Patients with acute coronary syndrome (ACS) constitute a very diverse group in terms of the severity and course of the disease, pharmacotherapy applied, and effort tolerance. Medical diagnosis is always accompanied by patients' subjective assessment of their health status and health-related quality of life (HRQOL). When studying the consequences of cardiovascular disease in clinical research, attention has been mostly paid to risk of death, survival time, other serious disorders resulting from the primary disease, physical condition, pain symptoms, and the possibility of working. ${ }^{1}$ Factors which are increasingly being taken into account in these analyses include: patients' use of medical consultation, their physical activity, socio-economic status, sexual life, satisfaction with the therapy and medical consultation, the reactions of patients'
Correspondence: Izabella Uchmanowicz Public Health Department, Wroclaw Medical University, Bartla 5, 5I-6I8, Wroclaw, Poland

Tel +48 7। 784 I857

Fax +48 7I 3459324

Email izabella.uchmanowicz@am.wroc.pl 
relatives to their disease, patients' mental state (emotions, self-assessment), their perception of their health status and the possibility of a return to "normal life", and their understanding of the role that they play in the healing process. Another important aspect is the influence of anxiety and depression on the HRQOL of cardiovascular patients. Both the medical and the psychological literatures contain quite a number of publications dealing with the problem of anxiety. Most studies concern anxiety caused by somatic diseases, perisurgical anxiety, psychosocial problems of patients after a myocardial infarction, and effects of cardiac rehabilitation. ${ }^{2-4}$ Anxiety is regarded as the most frequent emotional response to a disease and related medical procedures. Anxiety reactions are associated with uncertainty about the results of surgery, and a fear of pain and death. ${ }^{5,6}$ The level of patients' anxiety is also related to their expectations and cognitive reactions to medical procedures. Hence, some researchers claim that providing patients with information about surgery and a hospital stay may reduce their anxiety and help them to adapt to hospital routines and meet the constraints of the convalescent period. Cooperation between patients and medical workers, such as physicians, nurses, and physiotherapists, reduces patients' anxiety and improves their quality of life, ${ }^{7}$ consequently increasing their independence and motivation to act. People after a myocardial infarction constitute a special group of patients. Available results suggest that anxiety is a variable that has significant effects on the HRQOL of patients after a myocardial infarction and that plays an important role both during early therapy and at the further stages of the recovery process. ${ }^{4,8}$ Modern treatment methods for ACS enable efficient therapy, but at the same time produce a lot of psychological problems. Depressive symptoms occur in $45 \%$ of patients hospitalized for ACS, impeding the therapeutic process, increasing risk of early and late death, and lowering their quality of life. ${ }^{8,9}$

Furthermore, $25 \%-30 \%$ of patients live with a permanent feeling of anxiety about their health, which may contribute to the development of depression and a decline in quality of life. ${ }^{10,11}$

The conclusions drawn from these observations seem unambiguous. People who suffer from depressive disorders experience a substantial decline in HRQOL. Numerous studies show that the latter can be improved by an appropriate and effective therapy for depressive symptoms combined with psychotherapy. ${ }^{12-15}$ In this paper HRQOL is defined as people's perception of their position in life in the context of the culture and value system in which they live and in relation to their goals, expectations, standards, and concerns. ${ }^{16}$
The understanding of HRQOL issues allows us to collect a number of data points, to find correlations between them, and to identify those elements that can be improved or changed in the therapeutic process. Despite recent advances in treatment for ACS, a distant prognosis is not always satisfactory. We also do not know how the HRQOL of this group of patients changes with time. Available literature provides little information about this problem.

\section{Research premises and objectives}

The purposes of the study described in this article are:

1. to compare HRQOL of 90 ACS patients receiving percutaneous coronary intervention (PCI) during a 3-year observation period;

2. to detect whether depressive symptoms and the level of anxiety have an influence on the HRQOL of patients with ACS (N-STEMI and STEMI) receiving PCI;

3. to determine the dynamics of changes in the HRQOL of patients in the first week, sixth month, and 36th month after PCI;

4. to find any differences in the HRQOL of patients along lines of sex.

\section{Research material \\ Study design}

The study involved 90 patients (55 men, 35 women) aged 39-84 (mean age 61.9 years) hospitalized due to ACS and who qualified for coronary angioplasty in the cardiology ward at the T Marciniak Lower Silesian Specialist Hospital in Wroclaw, Poland.

Diagnosis of a clinical form of ACS was based on the criteria accepted by Polish and European Societies of Cardiology. The severity of coronary heart disease was determined in relation to the number of atherosclerotically changed coronary arteries in coronarography. The degree of impairment of the left ventricular function was estimated on the basis of an ejection fraction in echocardiography. In this prospective study the HRQOL was assessed thrice: in the first week, sixth month, and 36th month after PCI.

Socio-demographic data (age, sex, marital status, domicile, and education) were collected from all participants by means of a questionnaire. All respondents were informed in writing about the details of the study and that their participation was voluntary and anonymous. At the first stage of the study (in the first week after PCI) questionnaires were completed in the presence of a researcher. At the second and the third stage of the study questionnaires were sent to respondents and after completion sent back in a paid 
envelope. If patients did respond, the authors got in touch with them by phone and sent the questionnaires again. Completed data in the 36th month after surgery had been obtained from 90 participants. At the beginning of the study there were 120 patients; however, nine of them died and 21 did not send back their questionnaires. Thus, the authors took into consideration 90 patients who provided all required data at the first (baseline), second (sixth month) and third (36th month) stage of the study.

This study was approved by the Bioethical Commission of the Medical University of Wroclaw (No KB-743/2004 and KB-852/2012).

\section{Methodology Health-related quality-of-life instruments} HRQOL was measured using the Medical Outcomes Study 36-item Short-Form Survey (SF-36), Polish version. ${ }^{17}$ The SF-36 measures eight generic health categories: physical functioning $(\mathrm{PF})$, role limitations due to physical problems (RP), bodily pain (BP), general health (GH), vitality (VT), social functioning (SF), role limitations due to emotional problems (RE), and mental health $(\mathrm{MH})$. Subscale scores range from 0 to 100 , with higher scores signifying greater HRQOL. The physical subscales, measuring physical problems, pain, and self-rated health, constitute a physical component scale (PCS). The mental subscales, measuring daily functioning in relation to psychological issues and VT, constitute a mental component scale (MCS).

\section{Mental disorders}

An analysis of depressive symptoms was performed using the Beck Depression Inventory (BDI), ${ }^{18}$ which takes into account the most common signs of depression, such as: sadness, pessimism, feeling of inadequacy, loss of satisfaction, sense of guilt, expecting punishment, lack of self-acceptance, self-accusation, suicidal ideation, calling for help, irritability, withdrawal from social contact, indecisiveness, negative body-image, problems at work, sleep disorders, fatigue, loss of appetite, and weight loss.

The level of anxiety was determined using the Polish adaptation of the State-Trait Anxiety Inventory (STAI) ${ }^{19,20}$ developed by CD Spielberger, RL Goursuch, and RE Lushen in 1970. The STAI is an instrument for measuring anxiety understood as a temporary mental state of a person, which is conditioned by a situation, and anxiety recognized as a relatively permanent personality trait. The STAI consists of two sub-scales: (X-1) measuring anxiety as a state, and (X-2) concerning anxiety as a trait.

\section{Statistical analysis}

The statistical analysis was supported by Microsoft Excel in combination with the Statistica 10 PL package, and the following methods of statistical analysis were used: to test significance: Student's $t$-test for unrelated variables and chi-squared test for independent features; to test the effect of independent variables on quality of life factors: multiple regression; an influence of explanatory (independent) variables on the QOL assessment expressed in points (SF-36) was evaluated using a multiple regression analysis.

\section{Results}

In the study group, on average the women were approximately 5 years older than the men, and the difference was statistically significant $(P=0.08)$. There were also significantly more pensioners $(P=0.03)$ and male smokers $(P<0.001)$, and more married subjects $(P=0.003)$ (Table 1$)$.

An analysis of the dynamics of changes in the physical domain (PCS) revealed an unfavorable trend in the 36th month after surgery: 40.8 in the first week versus (vs) 41 in the sixth month vs 33.9 in the 36th month $(P<0.001)$. The differences between these values were statistically significant. The results are shown in Table 2.

Table I Socio-demographic and clinical characteristics of the study group by sex

\begin{tabular}{|c|c|c|c|c|}
\hline & $\begin{array}{l}\text { Study } \\
\text { group } \\
\mathbf{N}=90\end{array}$ & $\begin{array}{l}\text { Women } \\
\mathbf{N}=35 \\
(39 \%)\end{array}$ & $\begin{array}{l}\text { Men } \\
N=55 \\
(61 \%)\end{array}$ & P-value \\
\hline \multicolumn{5}{|c|}{ Demographic characteristics } \\
\hline Age & 61.12 & 64.43 & 59.02 & 0.08 \\
\hline Education & & & & 0.34 \\
\hline Primary & 22 & II & II & \\
\hline Vocational & 30 & 8 & 22 & \\
\hline Secondary & 35 & 15 & 20 & \\
\hline Higher & 3 & 1 & 2 & \\
\hline Unattached people & 22 & 15 & 7 & 0.003 \\
\hline Employed & 27 & 6 & 21 & 0.03 \\
\hline Pensioners & 63 & 29 & 34 & \\
\hline \multicolumn{5}{|c|}{ Clinical characteristics } \\
\hline Multi-vessel disease & 83 & 31 & 52 & 0.31 \\
\hline $\begin{array}{l}\text { Left ventricular } \\
\text { ejection fraction }\end{array}$ & 50.9 & 51.7 & 50.4 & 0.59 \\
\hline \multicolumn{5}{|l|}{ Risk factors } \\
\hline Diabetes & 45 & 19 & 26 & 0.52 \\
\hline Active smokers & 46 & 7 & 39 & $<0.001$ \\
\hline Hypertension & 60 & 24 & 36 & 0.76 \\
\hline Total cholesterol & 207.3 & 203.8 & 209.5 & 0.41 \\
\hline HDL & 47.9 & 48.5 & 47.4 & 0.56 \\
\hline LDL & 135.2 & 136.0 & 134.6 & 0.84 \\
\hline Obesity & II & 3 & 8 & 0.39 \\
\hline
\end{tabular}

Abbreviations: HDL, high-density lipoprotein; LDL, low-density lipoprotein. 
Table 2 Total QOL scores (mean, standard deviation) of the physical component scale (PCS) and mental component scale (MCS) in the first week, sixth month, and 36th month after PCl

\begin{tabular}{|c|c|c|c|c|c|c|c|}
\hline & \multicolumn{2}{|c|}{$\begin{array}{l}\text { First } \\
\text { week }\end{array}$} & \multicolumn{2}{|c|}{$\begin{array}{l}\text { Sixth } \\
\text { month }\end{array}$} & \multicolumn{2}{|c|}{$\begin{array}{l}\text { 36th } \\
\text { month }\end{array}$} & \multirow[t]{2}{*}{$P$-value } \\
\hline & $\overline{\mathbf{x}}$ & $\sigma$ & $\bar{x}$ & $\sigma$ & $\bar{x}$ & $\Sigma$ & \\
\hline SF-36 PCS & 40.8 & 1.2 & 41.0 & I.7 & 33.9 & 6.5 & $<0.001$ \\
\hline SF-36 MCS & 43.4 & 1.5 & 43.6 & 1.7 & 36.6 & 6 & $<0.001$ \\
\hline
\end{tabular}

Abbreviations: $\mathrm{QOL}$, quality of life; $\mathrm{PCl}$, percutaneous coronary intervention; SF36, 36-item Short-Form.

Similarly, an analysis of the dynamics of changes in the mental domain (MCS) demonstrated an unfavorable trend in the 36th month after surgery: 43.4 in the first week vs 43.6 in the sixth month vs 36.6 in the 36th month $(P<0.001)$. The results are shown in Table 2.

\section{HRQOL scores in particular SF-36 domains}

The PF scores of ACS patients receiving angioplasty treatment showed a changing trend: 53.9 in the first week vs 54.6 in the sixth month vs 50.2 in the 36 th month after a slight increase in the sixth month, the PF scores decreased $(P<0.001)$. The results are shown in Table 3 and Figure 1.

An analysis of the dynamics of changes in the RP domain also demonstrated a changing trend: 55.4 in the first week increased to 56.4 in the sixth month, and then decreased to a very low level of 28.2 in the 36th month $(P<0.001)$. The results are shown in Table 3 and Figure 1.

Table 3 QOL scores (mean, standard deviation) in the first week, sixth month and 36th month after $\mathrm{PCl}$

\begin{tabular}{|c|c|c|c|c|c|c|c|}
\hline & \multicolumn{2}{|c|}{$\begin{array}{l}\text { First } \\
\text { week }\end{array}$} & \multicolumn{2}{|c|}{$\begin{array}{l}\text { Sixth } \\
\text { month }\end{array}$} & \multicolumn{2}{|c|}{$\begin{array}{l}\text { 36th } \\
\text { month }\end{array}$} & \multirow[t]{2}{*}{$P$-value } \\
\hline & $\bar{x}$ & $\sigma$ & $\bar{x}$ & $\sigma$ & $\bar{x}$ & $\Sigma$ & \\
\hline SF-36 PF & 53.9 & 3.5 & 54.6 & 6.9 & 50.2 & 19.9 & $<0.001$ \\
\hline SF-36 RP & 55.4 & 3.2 & 56.4 & 3.4 & 28.2 & 27.7 & $<0.001$ \\
\hline SF-36 BP & 56.6 & 3.3 & 57.3 & 3.2 & 44.1 & 18.3 & $<0.001$ \\
\hline SF-36 GH & 57.1 & 2.8 & 57.1 & 2.9 & 36.3 & 9.7 & $<0.001$ \\
\hline SF-36 VT & 54.5 & 3.0 & 57.0 & 3.2 & 39.9 & 8.1 & $<0.001$ \\
\hline SF-36 SF & 57.0 & 3.2 & 57.1 & 4.3 & 40.1 & 16.7 & $<0.001$ \\
\hline SF-36 RE & 57.4 & 3.8 & 58.0 & 3.7 & 44.5 & 22.8 & $<0.001$ \\
\hline SF-36 MH & 57.4 & 3.3 & 58.3 & 3.7 & 49.1 & 10.4 & $<0.001$ \\
\hline SF-36 PCS & 40.8 & 1.2 & 41.0 & 1.7 & 34.8 & 6.4 & $<0.001$ \\
\hline SF-36 MCS & 43.4 & 1.5 & 43.6 & 1.7 & 37.4 & 5.8 & $<0.001$ \\
\hline
\end{tabular}

Abbreviations: $\mathrm{QOL}$, quality of life; $\mathrm{PCl}$, percutaneous coronary intervention; SF36, 36-item Short-Form; PF, physical functioning; RP, role limitations due to physical problems; BP, bodily pain; GH, general health; VT, vitality; SF, social functioning; $\mathrm{RE}$, role limitations due to emotional problems; $\mathrm{MH}$, mental health; PCS, physical component scale; MCS, mental component scale.

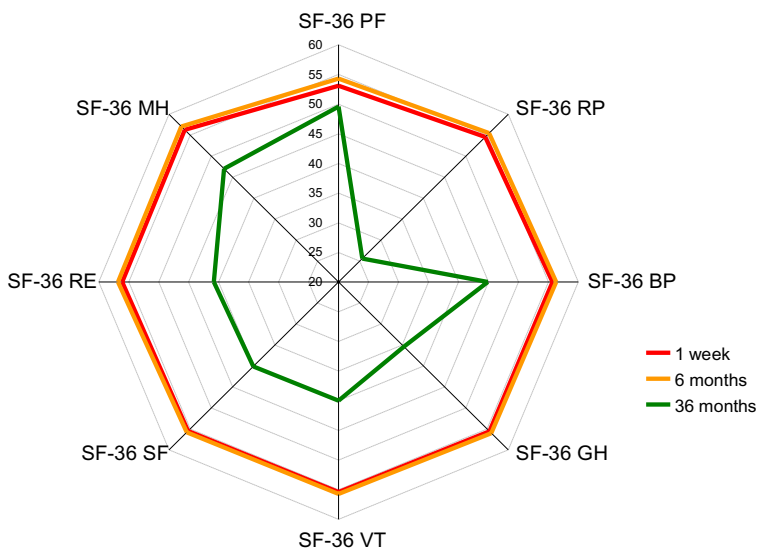

Figure I Comparison of the QOL levels in eight SF-36 domains at three periods of time.

Abbreviations: QOL, quality of life; SF-36, 36-item Short-Form; VT, vitality; SF, social functioning; RE, role limitations due to emotional problems; $\mathrm{MH}$, mental health; PF, physical functioning; RP, role limitations due to physical problems; BP, bodily pain; $\mathrm{GH}$, general health.

The BP score was 55.7 in the first week, then increased to 56.3 in the sixth month, and decreased to 44.9 in the 36th month $(P<0.0001)$. The results are shown in Table 3 and Figure 1.

An analysis of the dynamics of changes in the VT domain revealed a slight increase from the first week to the sixth month -54.5 vs 57.0 - and then a drop to $39.9(P<0.001)$. The results are shown in Table 3 and Figure 1.

The QOL levels decreased also in other SF-36 domains. A changing trend was noted in the GH domain: 57.1 in the first week vs 57.1 in the sixth month, and 36.3 in the 36th month $(P<0.001)$. The results are shown in Table 3 and Figure 1.

The score of the SF domain was 57.0 in the first week, 57.1 in the sixth month, and 40.1 in the 36 th month. The results are shown in Table 3 and Figure 1.

The RE score at first increased: 57.4 in the first week vs 58.0 in the sixth month - and then dropped to 44.5 in the 36th month $(P<0.001)$. The results are shown in Table 3 and Figure 1.

An analysis of the dynamics of changes in the $\mathrm{MH}$ domain also confirmed an unfavorable trend: 57.4 in the first week vs 58.3 in the sixth month and a decrease to 49.1 in the 36th month. The results are shown in Table 3 and Figure 1.

The results obtained by the study group suggest a decline in the QOL level of ACS patients in all eight SF-36 domains PF, RP, BP, GH, SF, VT, RE, MH during the 36 month observation period. The results are shown in Table 3 and Figure 1.

Thus, the QOL level declined in both the physical and the mental domain (PCS: 40.8 vs $34.8 ; P<0.001$; MCS: 43.4 vs $37.4 ; P<0.001)$. The results are shown in Table 3 and Figure 1. 
Women had lower total scores than men in both QOL domains (PCS: 32.1 vs $35.2 ; P=0.03$; MCS: 34.8 vs 37.8 ; $P=0.02$ ). The results are shown in Table 4 .

An analysis of the dynamics of changes in the severity of depressive symptoms according to the BDI shows an increase from 4.6 in the first week to 10.4 points in the 36th month $(P<0.001)$. The results are shown in Table 5 .

Changes in the levels of anxiety as a state and anxiety as a trait also showed an unfavorable trend: STAI-state: 28.5 in the first week vs 34.3 in the 36th month $(P<0.001)$; STAI-trait: 30.0 in the first week vs 33.9 in the 36 th month $(P<0.001)$ (Table 5).

In the group of women, an analysis of the dynamics of changes in the severity of depressive symptoms according to the BDI demonstrated an increase from 3.9 points in the first week to 9.5 points in the 36th month $(P<0.001)$. The results are shown in Table 6.

Changes in the levels of anxiety as a state and anxiety as a trait also showed an unfavorable trend: STAI-state: 28 in the first week vs 33.8 in the 36th month $(P<0.001)$; STAItrait: 29.4 vs $33.3(P<0.001)$ (Table 6$)$.

In the group of men, an analysis of the dynamics of changes in the severity of depresive symptoms according to the BDI demonstrated an increase from 5.1 points in the first week to 10.9 points in the 36th month $(P<0.001)$. The results are shown in Table 7.

Changes in the levels of anxiety as a state and anxiety as a trait also showed an unfavorable trend: STAI-state: 28.9 in the first week vs 34.9 in the 36th month $(P<0.001)$; STAItrait: 30.4 vs $34.4(P<0.001)$.

\section{Multiple regression}

An influence of explanatory (independent) variables on the QOL assessment expressed in points (SF-36) was evaluated using a multiple regression analysis. The following factors (explanatory variables) were included in the QOL model:

- $\mathrm{X}_{1}$ : Age (year of life)

- $\mathrm{X}_{2}$ : Sex $(1-$ woman, $-1-\operatorname{man})$

- $\mathrm{X}_{3}$ : STAI-trait (points)

Table 4 Total QOL scores (mean, standard deviation) of the physical component scale (PCS) and mental component scale (MCS) by sex

\begin{tabular}{lllllll}
\hline & Men & & & \multicolumn{2}{c}{ Women } & P-value \\
\cline { 2 - 3 } & $\overline{\boldsymbol{x}}$ & $\boldsymbol{\sigma}$ & & $\overline{\boldsymbol{x}}$ & $\boldsymbol{\Sigma}$ & \\
\hline SF-36 PCS & 35.2 & 7.1 & & 32.1 & 5.2 & 0.03 \\
SF-36 MCS & 37.8 & 5.8 & & 34.8 & 5.8 & 0.02 \\
\hline
\end{tabular}

Abbreviations: QOL, quality of life; SF-36, 36-item Short-Form.
Table 5 QOL scores (mean, standard deviation) according to the STAI and the BDI in the first week, sixth month, and 36th month after $\mathrm{PCl}$

\begin{tabular}{|c|c|c|c|c|c|c|c|}
\hline & \multicolumn{2}{|c|}{$\begin{array}{l}\text { First } \\
\text { week }\end{array}$} & \multicolumn{2}{|c|}{$\begin{array}{l}\text { Sixth } \\
\text { month }\end{array}$} & \multicolumn{2}{|c|}{$\begin{array}{l}\text { 36th } \\
\text { month }\end{array}$} & \multirow[t]{2}{*}{$P$-value } \\
\hline & $\bar{x}$ & $\sigma$ & $\bar{x}$ & $\sigma$ & $\bar{x}$ & $\sigma$ & \\
\hline BDI & 4.6 & 4.7 & 6.7 & 5.2 & 10.4 & 4.4 & $<0.001$ \\
\hline STAI-state & 28.5 & 3.7 & 31.8 & 3.2 & 34.3 & 3.8 & $<0.001$ \\
\hline STAI-trait & 30.0 & 3.7 & 31.9 & 3.6 & 33.9 & 3.3 & $<0.001$ \\
\hline
\end{tabular}

Abbreviations: QOL, quality of life; STAI, State-Trait Anxiety Inventory; BDI, Beck Depression Inventory; $\mathrm{PCl}$, percutaneous coronary intervention.

- $\mathrm{X}_{4}$ : STAI-state (points)

$-\mathrm{X}_{5}$ : BDI (points)

\section{The PF domain}

The PF domain is negatively affected by age, the level of anxiety as a trait, and the severity of depressive symptoms. Women score lower in this domain than men. The coefficient of determination $R^{2}=0.6034$ means that $50.34 \%$ of the QOL score in the PF domain is explained by this model (Table 8).

\section{The RP domain}

The assessment of the RP domain was negatively influenced by age, the level of anxiety, and the severity of depressive symptoms. Women have lower scores in this domain than men. The coefficient of determination $R^{2}=0.7118$ means that $71.18 \%$ of the QOL score in the RP domain is explained by this model (Table 9).

\section{The BP domain}

The BP model established by the method of least squares takes the following form: the BP domain is negatively influenced by age, the level of anxiety, and the severity of depressive symptoms. Women score higher in this domain than men. The coefficient of determination $R^{2}=0.5887$ means that $58.87 \%$ of the QOL score in the BP domain is explained by this model (Table 10).

Table 6 QOL scores of women (mean, standard deviation) according to the STAI and the BDI in the first week, sixth month, and 36th month after $\mathrm{PCl}$

\begin{tabular}{|c|c|c|c|c|c|c|c|}
\hline & \multicolumn{2}{|c|}{$\begin{array}{l}\text { First } \\
\text { week }\end{array}$} & \multicolumn{2}{|c|}{$\begin{array}{l}\text { Sixth } \\
\text { month }\end{array}$} & \multicolumn{2}{|c|}{$\begin{array}{l}\text { 36th } \\
\text { month }\end{array}$} & \multirow[t]{2}{*}{$P$-value } \\
\hline & $\bar{x}$ & $\sigma$ & $\bar{x}$ & $\sigma$ & $\bar{x}$ & $\sigma$ & \\
\hline BDI & 3.9 & 3.9 & 6.3 & 4.5 & 9.5 & 4.0 & $<0.001$ \\
\hline STAI-state & 28 & 3.7 & 31.4 & 2.9 & 33.8 & 3.9 & $<0.001$ \\
\hline STAI-trait & 29.4 & 3.4 & 31.5 & 3.0 & 33.3 & 3.2 & $<0.001$ \\
\hline
\end{tabular}

Abbreviations: $\mathrm{QOL}$, quality of life; STAl, State-Trait Anxiety Inven
Depression Inventory; $\mathrm{PCl}$, percutaneous coronary intervention. 
Table 7 QOL scores of men (mean, standard deviation) according to the STAI and the BDI in the first week, sixth month, and 36th month after $\mathrm{PCl}$

\begin{tabular}{|c|c|c|c|c|c|c|c|}
\hline & \multicolumn{2}{|c|}{$\begin{array}{l}\text { First } \\
\text { week }\end{array}$} & \multicolumn{2}{|c|}{$\begin{array}{l}\text { Sixth } \\
\text { month }\end{array}$} & \multicolumn{2}{|c|}{$\begin{array}{l}\text { 36th } \\
\text { month }\end{array}$} & \multirow[t]{2}{*}{$P$-value } \\
\hline & $\bar{x}$ & $\sigma$ & $\bar{x}$ & $\sigma$ & $\bar{x}$ & $\sigma$ & \\
\hline BDI & 5.1 & 5.2 & 7.1 & 5.6 & 10.9 & 4.5 & $<0.001$ \\
\hline STAI-state & 28.9 & 3.8 & 32.0 & 3.5 & 34.6 & 3.8 & $<0.001$ \\
\hline STAI-trait & 30.4 & 3.8 & 32.2 & 4.0 & 34.4 & 3.4 & $<0.001$ \\
\hline
\end{tabular}

Abbreviations: QOL, quality of life; STAI, State-Trait Anxiety Inventory; BDI, Beck Depression Inventory; $\mathrm{PCl}$, percutaneous coronary intervention.

\section{The GH domain}

The GH domain is negatively influenced by age, and positively by the severity of depressive symptoms. Women score lower in this domain than men. The coefficient of determination $R^{2}=0.599$ means that $59.9 \%$ of the QOL score in the GH domain is explained by this model (Table 11).

\section{The VT domain}

QOL in the VT domain is negatively affected by age, the level of anxiety as a trait, and the severity of depressive symptoms. Women score lower in this domain than men. The coefficient of determination $R^{2}=0.6219$ means that $62.19 \%$ of the QOL score in the VT domain is explained by this model (Table 12).

\section{The SF domain}

QOL in the SF domain is negatively affected by age, and the level of anxiety as a trait and as a state. The coefficient of determination $R^{2}=0.5143$ means that $51.43 \%$ of the QOL score in the SF domain is explained by this model (Table 13).

\section{The RE domain}

The RE domain is negatively affected by older age, and a higher level of anxiety as a state. Men show more limitations within this domain than women. The coefficient of determination $R^{2}=0.6595$ means that $65.95 \%$ of the QOL score in the RE domain is explained by this model (Table 14).

Table 8 Results of regression of a response (dependent) variable in the PF domain

\begin{tabular}{llll}
\hline $\mathbf{Y}=\mathbf{P F}$ & $\boldsymbol{\beta}$ & $\mathbf{X}_{\mathbf{i}}$ & $\boldsymbol{P}$-value \\
\hline Absolute term & & 98.43 & $0.00 \mathrm{I}$ \\
Age & -0.08 & -0.25 & 0.03 \\
Sex & 0.09 & $2.5 \mathrm{I}$ & 0.03 \\
STAl-trait & -0.05 & -0.49 & 0.04 \\
BDI & -0.24 & $-\mathrm{I} .55$ & 0.01 \\
\hline
\end{tabular}

Abbreviations: PF, physical functioning; STAI, State-Trait Anxiety Inventory; BDI, Beck Depression Inventory.
Table 9 Results of regression of a response (dependent) variable in the RP domain

\begin{tabular}{llll}
\hline $\mathbf{Y = R P}$ & $\boldsymbol{\beta}$ & $\mathbf{X}_{\mathbf{i}}$ & $\boldsymbol{P}$-value \\
\hline Absolute term & & 52.41 & 0.01 \\
Age & -0.05 & -0.15 & 0.04 \\
Sex & -0.11 & -12.06 & 0.03 \\
STAI-trait & -0.45 & -0.81 & 0.001 \\
STAl-state & -0.43 & -0.31 & 0.001 \\
BDI & -0.22 & -1.41 & 0.01 \\
\hline
\end{tabular}

Abbreviations: STAI, State-Trait Anxiety Inventory; BDI, Beck Depression Inventory; RP, role limitations due to physical problems.

Table 10 Results of regression of a response (dependent) variable in the BP domain

\begin{tabular}{llll}
\hline $\mathbf{Y}=\mathbf{B P}$ & $\boldsymbol{\beta}$ & $\mathbf{X}_{\mathbf{i}}$ & $\boldsymbol{P}$-value \\
\hline Absolute term & & 40.8 & 0.01 \\
Age & -0.16 & -0.3 & 0.02 \\
Sex & 0.17 & 3.16 & 0.02 \\
STAl-trait & -0.25 & -1.46 & 0.01 \\
BDI & -0.28 & -1.19 & 0.01 \\
\hline
\end{tabular}

Abbreviations: STAI, State-Trait Anxiety Inventory; BDI, Beck Depression Inventory; BP, bodily pain.

Table II Results of regression of a response (dependent) variable in the $\mathrm{GH}$ domain

\begin{tabular}{llll}
\hline $\mathbf{Y}=\mathbf{G H}$ & $\boldsymbol{\beta}$ & $\mathbf{X}_{\mathbf{i}}$ & $\boldsymbol{P}$-value \\
\hline Absolute term & & 40.06 & 0.04 \\
Age & 0.16 & -0.03 & 0.02 \\
Sex & -0.17 & 0.91 & 0.02 \\
BDI & 0.28 & 0.54 & 0.01 \\
\hline
\end{tabular}

Abbreviations: BDI, Beck Depression Inventory; GH, general health.

Table 12 Results of regression of a response (dependent) variable in the VT domain

\begin{tabular}{llll}
\hline $\mathbf{Y}=\mathbf{V T}$ & $\boldsymbol{\beta}$ & $\mathbf{X}_{\mathbf{i}}$ & $\boldsymbol{P}$-value \\
\hline Absolute term & & 66.23 & $<0.001$ \\
Age & -0.31 & -0.26 & 0.01 \\
Sex & -0.09 & -0.7 & 0.03 \\
STAl-trait & -0.08 & -0.21 & 0.04 \\
BDI & -0.34 & -0.34 & 0.008 \\
\hline
\end{tabular}

Abbreviations: STAI, State-Trait Anxiety Inventory; BDI, Beck Depression Inventory; VT, vitality.

Table I 3 Results of regression of a response (dependent) variable in the SF domain

\begin{tabular}{llll}
\hline $\mathbf{Y}=\mathbf{S F}$ & $\boldsymbol{\beta}$ & $\mathbf{X}_{\mathbf{i}}$ & $\boldsymbol{P}$-value \\
\hline Absolute term & & $\mathrm{II} 8.24$ & $0.00 \mathrm{I}$ \\
Age & -0.17 & -0.29 & 0.02 \\
STAl-trait & -0.14 & -1.52 & 0.03 \\
STAl-state & -0.33 & -0.27 & 0.01 \\
\hline
\end{tabular}

Abbreviations: STAI, State-Trait Anxiety Inventory; SF, social functioning. 
Table I4 Results of regression of a response (dependent) variable in the $R E$ domain

\begin{tabular}{llll}
\hline $\mathbf{Y}=\mathbf{R E}$ & $\boldsymbol{\beta}$ & $\mathbf{X}_{\mathbf{i}}$ & $\boldsymbol{P}$-value \\
\hline Absolute term & & 40.58 & 0.001 \\
Age & -0.14 & -0.32 & 0.03 \\
Sex & 0.14 & 2.97 & 0.03 \\
STAl-state & -0.15 & -0.85 & 0.03 \\
BDI & -0.25 & -1.27 & 0.01 \\
\hline
\end{tabular}

Abbreviations: STAI, State-Trait Anxiety Inventory; BDI, Beck Depression Inventory; RE, role limitations due to emotional problems.

\section{The $\mathrm{MH}$ domain}

The MH domain is negatively influenced by the level of anxiety as a state, and the severity of depressive symptoms. The coefficient of determination $R^{2}=0.574$ means that $57.4 \%$ of the QOL score in the MH domain is explained by this model (Table 15).

\section{The self-rated QOL according to the PCS}

The QOL according to the PCS is negatively affected by the level of depressive symptoms. Women had significantly lower self-rated QOL in the physical domain. The coefficient of determination $R^{2}=0.623$ means that $62.3 \%$ of the QOL score in the physical domain is explained by this model (Table 16).

\section{Self-rated QOL according to the MCS}

QOL according to the MCS is positively influenced by age, and negatively by a high level of anxiety as a state. Women had significantly lower self-rated QOL in the mental domain. The coefficient of determination $R^{2}=0.692$ means that $69.2 \%$ of the QOL score in the mental domain is explained by this model (Table 17).

\section{Discussion}

The European Society of Cardiology has included HRQOL maintenance and improvement as treatment goals in their guidelines, both for patients with chronic heart failure and those with stable angina pectoris. ${ }^{21,22}$ There are few reports

Table 15 Results of regression of a response (dependent) variable in the $\mathrm{MH}$ domain

\begin{tabular}{llll}
\hline $\mathbf{Y}=\mathbf{M H}$ & $\boldsymbol{\beta}$ & $\mathbf{X}_{\mathbf{i}}$ & $\boldsymbol{P}$-value \\
\hline Absolute term & & -18.03 & 0.01 \\
STAl-state & 0.24 & 0.85 & 0.01 \\
BDI & 0.19 & 1.27 & 0.01 \\
\hline
\end{tabular}

Abbreviations: STAI, State-Trait Anxiety Inventory; BDI, Beck Depression Inventory; MH, mental health.
Table 16 Results of regression of a response (dependent) variable in the PCS

\begin{tabular}{llll}
\hline $\mathbf{Y}=$ PCS & $\boldsymbol{\beta}$ & $\mathbf{X}_{\mathbf{i}}$ & $\boldsymbol{P}$-value \\
\hline Absolute term & & 40.12 & $<0.001$ \\
Sex & -0.2 & -1.33 & 0.04 \\
BDI & -0.22 & -0.34 & 0.04 \\
\hline
\end{tabular}

Abbreviations: BDI, Beck Depression Inventory; PCS, physical component scale.

concerning factors contributing to the distant QOL of patients undergoing percutaneous coronary angioplasty. A 3-year prospective study described in this article demonstrated that after the study periods patients regarded their QOL level as considerably lower in all SF-36 domains. What is interesting is that at 1 st week and at 6 months after procedure patients perceived their QOL level as higher, even though this was also when they experienced higher anxiety and more severe depressive symptoms. The increase was statistically significant. Furthermore, there were differences in the subjective QOL assessment between sexes, which corresponds with the results reported by other authors. ${ }^{23}$ Women scored lower than men in all SF-36 domains.

Several previous studies suggested an increase in the QOL level after percutaneous coronary angioplasty, ${ }^{24}$ which was confirmed by the findings of this study after 6 months' observation. However, after the 36 month observation period QOL scores decreased in all domains. It should be emphasized that most studies last no longer than 1 year. ${ }^{25}$

In the study presented here, an increase in the level of anxiety as a state and anxiety as a trait was a determinant of a decline in QOL scores. Depressive symptoms also contributed to the lowering of the HRQOL level during the 36 month observation period. According to other researchers, depressive symptoms occur in as many as $45 \%$ of ACS patients, complicating the therapeutic process and increasing the risk of early and late mortality. ${ }^{26}$

In the Polish study conducted by Dudek et al, ${ }^{26}$ depression was a potential cause of the lack of improvement in some patients even after successful coronary angioplasty. Therefore, the early identification of depressive symptoms and an individual approach to a patient should contribute

Table 17 Results of regression of a response (dependent) variable in the MCS

\begin{tabular}{llll}
\hline $\mathbf{Y}=$ MCS & $\boldsymbol{\beta}$ & $\mathbf{X}_{\mathbf{i}}$ & $\boldsymbol{P}$-value \\
\hline Absolute term & & 14.95 & $<0.001$ \\
Age & 0.2 & 0.08 & 0.04 \\
Sex & -0.23 & -1.39 & 0.04 \\
STAl-state & -0.28 & -0.5 & 0.01 \\
\hline
\end{tabular}

Abbreviations: MCS, mental component scale; STAI, State-Trait Anxiety Inventory. 
to the improvement of patients' health status, and thus the reduction of medical expenses. The presence of depressive symptoms entails a poorer response to the treatment applied. Wrześniewski underlines that, even more than 10 years after a myocardial infarction, anxiety associated with heart attack may be destructive for the functioning of a person. ${ }^{4} \mathrm{~A}$ similar correlation was demonstrated by Fauerbach et al, ${ }^{27}$ who indicated that there was a relationship between depression among ACS patients and the lowering of their QOL level. Patients with depression scored significantly lower in both the physical and the mental domain of the SF-36 questionnaire than their counterparts without this health problem. ${ }^{27,28}$ The research of Grace et $\mathrm{al}^{29}$ confirmed that depression occurring during hospitalization after ACS contributes to the longlasting worsening of HRQOL and increases the risk of death for cardiovascular reasons for up to 5 years after ACS.

Studies concerning anxiety issues are not numerous. Some researchers claim that anxiety can be treated as a risk factor of further cardiac events. ${ }^{30}$ The study described in this article shows that more attention should be paid to anxiety accompanying cardiovascular diseases.

\section{Study limitations}

We are well aware of the potential limitations of this study. The most important of these stem from the fact that our study sample was relatively small and recruited from a single center. We plan to extend our research on this subject in the future.

\section{Conclusion}

There is a relationship between HRQOL measured with the SF-36 questionnaire and such variables as sex, age, anxiety and depressive symptoms.

The results of this study demonstrate that more attention should be focused on the distant quality of life of ACS patients after PCI, and especially on their mental and physical status.

\section{Disclosure}

The authors have no conflicts of interest to disclose.

\section{References}

1. Graf J, Koch M, Dujardin R, Kersten A, Janssens U. Health-related quality of life before, 1 month after, and 9 months after intensive care in medical cardiovascular and pulmonary patients. Crit Care Med. 2003;31(8):2163-2169.

2. Haas DC. Depression and disability in coronary patients: time to focus on quality of life as an endpoint. Heart. 2006;92(1):8-10.

3. Lane D, Carroll D, Ring C, Beevers DG, Lip GY. Mortality and quality of life 12 months after myocardial infarction: effects of depression and anxiety. Psychosom Med. 2001;63(2):221-230.
4. Wrześniewski K. Psychologiczne problemy chorych z zawatem serca. 2nd ed. Warsaw: PZWL; 1986:40-110. Polish.

5. Heszen-Niejodek I. Styl radzenia sobie ze stresem: fakty i kontrowersje. Czasopismo Psychologiczne. 1997;3(1):7-22. Polish.

6. Phipps W, Sands J, Marek J. Medical Surgical Nursing: Health and Illness Perspectives. 7th ed. St Louis: Mosby; 2003.

7. Daugherty C, Dewhurst W, Spertus J. Health related quality of life outcomes in clinical research. American Journal of Epidemiology. 1998;51:569-575.

8. Pettersen KI, Reikvam A, Rollag A, Stavem K. Understanding sex differences in health-related quality of life following myocardial infarction. Int J Cardiol. 2008;130(3):449-456.

9. Mayou RA, Gill D, Thompson DR, et al. Depression and anxiety as predictors of outcome after myocardial infarction. Psychosom Med. 2000;62(2):212-219.

10. Beck CA, Joseph L, Belisle P. Predictors of quality of life 6 months and 1 year after myocardial infarction. Am Heart J. 2001;142(2): 271-279.

11. Lane D, Caroll D, Ring C, Beevers DG, Lip GY. Effects of depression and anxiety on mortality and quality of life 4 months after myocardial infarction. J Psychosom Res. 2001;49(4):229-239.

12. Swenson JR. Quality of life in patients with coronary artery disease and the impact of depression. Curr Psychiatry Rep. 2004;6(6):438-445.

13. Stewart T, Yusim A, Desan P. Depression as a risk factor for cardiovascular disease. Primary Psychiatry. 2005;12(5):36-41.

14. Carney RM, Blumenthal JA, Catellier D, et al. Depression as a risk factor for mortality after acute myocardial infarction. Am J Cardiol. 2003;92(11):1277-1281.

15. Lesperance F, Frasure-Smith N, Juneau M, Theroux P. Depression and 1-year prognosis in unstable angina. Arch Intern Med. 2000;160(9): 1354-1360.

16. No authors listed. World Health Organization Quality of Life assessment (WHOQOL): position paper from the World Health Organization. Soc Sci Med. 1995;41(10):1403-1409.

17. McHorney CA, Ware JE Jr, Raczek AE. The MOS 36-Item Short-Form Health Survey (SF-36): II. Psychometric and clinical tests of validity in measuring physical and mental health constructs. Med Care. 1993;31(3): 247-263.

18. Beck AT, Ward CH, Mendelson M, Mock J, Erbaugh J. An inventory for measuring depression. Arch Gen Psychiatry. 1961;4:561-571.

19. Spielberger CD. Theory and Research on Anxiety. New York: Academic Press; 1966.

20. Juczyński Z, Ogińska-Bulik N. Narzędzia pomiaru stresu i radzenia sobie ze stresem. Warsaw:Pracowania Testów Psychologicznych; 2009. Polish.

21. McMurray JV, Adamopoulos S, Anker SD, et al. ESC Guidelines for the diagnosis and treatment of acute and chronic heart failure 2012: The Task Force for the Diagnosis and Treatment of Acute and Chronic Heart Failure 2012 of the European Society of Cardiology. Developed in collaboration with the Heart Failure Association (HFA) of the ESC. Eur J Heart Fail. 2012;14(8):803-869.

22. Fox K, Garcia MA, Ardissino D, et al. Guidelines on the management of stable angina pectoris: executive summary: the Task Force on the Management of Stable Angina Pectoris of the European Society of Cardiology. Eur Heart J. 2006;27(11):1341-1381.

23. Norris CM, Hegadoren K, Pilote L. Depression symptoms have a greater impact on the 1-year health-related quality of life outcomes of women post-myocardial infarction compared to men. Eur J Cardiovasc Nurs. 2007;6(2):92-98.

24. Rumsfeld JS, Magid DJ, Plomondon ME, et al. History of depression, angina, and quality of life after acute coronary syndromes. Am Heart J. 2003;145(3):493-499.

25. de Jonge P, Spijkerman TA, van den Brink RH, Ormel J. Depression after myocardial infarction is a risk factor for declining health related quality of life and increased disability and cardiac complaints at 12 months. Heart. 2006;92(1):32-39. 
26. Dudek D, Wróbel A, Bartuś S, et al. Relationship between depressive symptoms and quality of life patients with coronary artery disease after percutaneous coronary interventions. Kardiologia Polska. 2000; 53(7):14-17.

27. Fauerbach JA, Bush D, Thombs BD, McCann UD, Fogel J, Ziegelstein RC. Depression following acute myocardial infarction: a prospective relationship with ongoing health and function. Psychosomatics. 2005;46(4):355-361.

28. Jankowska-Polańsk B, Uchmanowicz I, Dudek, K, ŁobozGrudzień K. Gender differences in depressive symptoms associated with acute coronary syndrome. Polski Przeglad Kardiologiczny. 2012;14(3):180-185.
29. Grace SL, Abbey SE, Kapral MK, et al. Effect of depression on five-year mortality after an acute coronary syndrome. Am J Cardiol. 2005;96(9):1179-1185.

30. Benninghoven D, Kaduk A, Wiegand U, Specht T, Kunzendorf S, Jantschek G. Influence of anxiety on the course of heart disease after acute myocardial infarction - risk factor or protective function? Psychother Psychosom. 2006;75(1):56-61.

\section{Publish your work in this journal}

Nursing: Research and Reviews is an international, peer-reviewed, open access journal publishing original research, reports, reviews and commentaries on all aspects of nursing and patient care. These include patient education and counselling, ethics, management and organizational issues, diagnostics and prescribing, economics and

\section{Dovepress}

resource management, health outcomes, and improving patient safety in all settings. The manuscript management system is completely online and includes a very quick and fair peer-review system. Visit http://www.dovepress.com/testimonials.php to read real quotes from published authors.

Submit your manuscript here: http://www.dovepress.com/nursing-research-and-reviews-journal 